\title{
The climatic effects of the direct injection of water vapour into the stratosphere by large volcanic eruptions
}

\author{
M. M. Joshi ${ }^{1}$ and G. S. Jones ${ }^{2}$ \\ ${ }^{1}$ NCAS Climate, University of Reading, UK \\ ${ }^{2}$ Hadley Centre for Climate Change, Met Office, UK \\ Received: 20 January 2009 - Published in Atmos. Chem. Phys. Discuss.: 2 March 2009 \\ Revised: 7 August 2009 - Accepted: 10 August 2009 - Published: 25 August 2009
}

\begin{abstract}
We describe a novel mechanism that can significantly lower the amplitude of the climatic response to certain large volcanic eruptions and examine its impact with a coupled ocean-atmosphere climate model. If sufficiently large amounts of water vapour enter the stratosphere, a climatically significant amount of water vapour can be left over in the lower stratosphere after the eruption, even after sulphate aerosol formation. This excess stratospheric humidity warms the tropospheric climate, and acts to balance the climatic cooling induced by the volcanic aerosol, especially because the humidity anomaly lasts for a period that is longer than the residence time of aerosol in the stratosphere. In particular, northern hemisphere high latitude cooling is reduced in magnitude. We discuss this mechanism in the context of the discrepancy between the observed and modelled cooling following the Krakatau eruption in 1883. We hypothesize that moist coignimbrite plumes caused by pyroclastic flows travelling over ocean rather than land, resulting from an eruption close enough to the ocean, might provide the additional source of stratospheric water vapour.
\end{abstract}

\section{Introduction}

Volcanic eruptions have the capacity to dramatically alter global climate on long climatic timescales. Large explosive eruptions affect climate by injecting $\mathrm{SO}_{2}$ into the stratosphere, which eventually combines with existing water vapour to form sulphate aerosols that scatter sunlight and cool the surface. The climatic effects of eruptions have been summarised by e.g. Robock (2000).

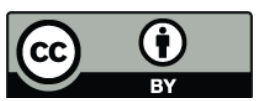

Correspondence to: M. M. Joshi (m.m.joshi@reading.ac.uk)
Here we describe a novel mechanism that might significantly alter the response of the climate to a large volcanic eruption: so much water vapour is directly injected into the stratosphere during certain eruptions that a climatically significant amount is left over after the formation of stratospheric sulphate aerosol. This stratospheric water vapour anomaly exerts a positive radiative forcing on the surface, offsetting the negative climate forcing from the volcanic stratospheric aerosol, leading to a surface temperature response that is smaller in amplitude (i.e. more positive) than if forced by the volcanic aerosol alone.

Different mechanisms have been suggested for increases in stratospheric humidity following eruptions. Joshi and Shine (2003) proposed that heating of the tropical tropopause layer by volcanic aerosol in the 2 years following the eruption allowed more water vapour into the stratosphere. Another mechanism is that water vapour enters the plumes of a major volcanic eruption by a number of different ways: from the magma itself (Scaillet et al., 2003); from interaction of the magma with water (phreatomagmatic eruptions) (Carey et al., 1996); from entrainment from the local environment (Glaze et al., 1997; Dartevelle et al., 2002). Whilst much of the water condenses out of the plume, enough may reach the stratosphere to significantly affect climate.

Here we investigate another mechanism, which is dependent on a volcano being in the vicinity of a large body of water. In this case, the injection of significant amounts of water into the stratosphere could be achieved by entrainment of large amounts of water into coignimbrite clouds (also known as "phoenix clouds") resulting from pyroclastic flows that travel over open water, as shown by the schematic in Fig. 1. When pyroclastic flows entrain local air and lose their denser components, lighter co-ignimbrite clouds loft off the flows and can become substantial plumes in their

Published by Copernicus Publications on behalf of the European Geosciences Union. 


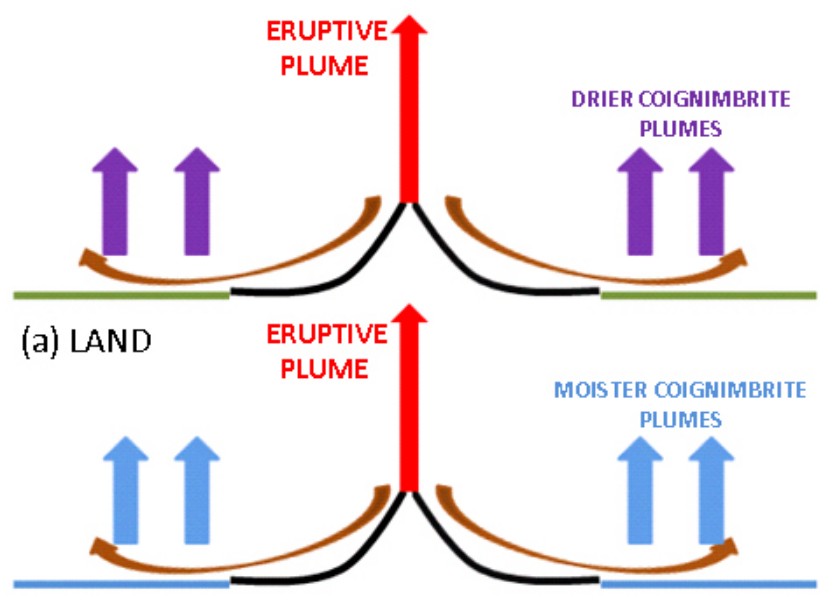

(b) OCEAN

Fig. 1. The difference between entrainment of moisture in an eruption that is landlocked (a) and an island (b): the magmatic plumes (red arrows) are similar, but the pyroclastic flow from the volcano (brown arrows) travel over the ocean in (b), and the moisture entrained into the resulting coignimbrite plumes is much higher (purple arrows in (a) and blue arrows in (b)).

own right reaching as high as the stratosphere (Woods and Wohletz, 1991; Dartevelle et al., 2002). In the landlocked case (Fig. 1a), a relatively small amount of evaporated water is entrained into the coignimbrite plumes. However, in the island case (Fig. 1b), much more water is evaporated from the ocean by the pyroclastic flows, with the coignimbrite plumes transporting this water vapour upwards. It has already been hypothesised that significant amounts of water can be entrained into coignimbrite ash clouds following eruptions and that pyroclastic flows over the sea can evaporate water which can contribute to the development of the coignimbrite plumes (Dartevelle et al., 2002; Carey et al., 1996; Francis and Self, 1983).

Previous studies have suggested possible inventories of stratospheric water vapour (hence SWV) resulting from volcanic eruptions; between $10 \mathrm{Mt}$ from magma (Pitari and Mancini, 2002) to $540 \mathrm{Mt}$ from magma and entrainment into the Plinian column from the atmosphere (Dartevelle et al., 2002) from Pinatubo's eruption in 1991. However, satellite observations of SWV in the months following the eruption imply a maximum value of $100-150 \mathrm{Mt}$ up to that time (Nedoluha et al., 1998). Estimates from other volcanic eruptions are $\sim 2$ Gt following Tambora in 1816 (Glaze et al., 1997) and $\sim 27 \mathrm{Gt}$ from the 76 kya Toba eruption (Bekki et al., 1996), both from estimates of water in the magma. The mechanism of sea-water entrainment into the plume (described above) could potentially significantly add to the amounts of water vapour injected into the stratosphere depending on the vicinity of the volcano to bodies of water.
SWV can have significant climatic effects; the radiative forcing due to SWV increases of O (1) ppm in the 20th century have been modelled as being up to $+0.5 \mathrm{Wm}^{-2}$ (e.g. Forster and Shine, 2002). A water vapour anomaly of $0.95 \mathrm{ppmm}$, or $\sim 1.5 \mathrm{ppmv}$ in the stratosphere is equivalent to a total mass of water of $500 \mathrm{Mt}$, which is entirely consistent with the inventories described above. The partial cancellation of volcanic cooling by direct injection of water into the stratosphere is therefore entirely plausible. Moreover, a humidity anomaly in the tropical lower stratosphere is distributed around the stratosphere by atmospheric motions, eventually dissipating on a timescale of 5-10 years (Hall and Waugh, 1997). By comparision, micron-sized sulphate aerosol droplets particles fall out of the stratosphere on a timescale of 2-3 years; the water vapour anomaly therefore outlasts the volcanic aerosol loading by some years.

In this work we shall examine the effects of direct injection using a parameterisation of injection on a state-of-the-art coupled ocean-atmosphere climate model which has the climatic effects of volcanic aerosol included in it. We then discuss the implications of the mechanism for certain specific eruptions, particularly Krakatau in 1883.

\section{Model setup}

The model used here is the Hadley Centre's new climate model HadGEM1 (Johns et al., 2006). The version used is the so-called "ALL" integration, which has all natural and anthropogenic forcings since 1860 (Stott et al. 2006). The primary effect of volcanoes on climate is the radiative heating effect of sulphate aerosol in the stratosphere produced from volcanic $\mathrm{SO}_{2}$ (Robock, 2000). HadGEM1 uses a monthly mean climatology of stratospheric volcanic aerosol optical depth which is converted into a mass mixing ratio and spread evenly above the tropopause. For more details the reader is referred to Stott et al. (2006), p2768-2769.

The model has 38 layers in the vertical, of which $\sim 10$ are in the stratosphere. The model's atmospheric performance has been comprehensively evaluated, and its simulation of phenomena relevant to this study, e.g. the tropical lower stratosphere SWV tape recorder, is adequate (Martin et al., 2006). In addition, the model has been used previously to investigate the climatic response to stratospheric anomalies (Joshi et al., 2006; Dall Amico et al., 2009). As shown later, the transport timescales in the model's stratosphere are consistent with previous work. The simulated global $1.5 \mathrm{~m}$ temperature response in HadGEM1 following the Mt Pinatubo eruption in 1991 is consistent with observed temperature variations (Stott et al., 2006; Jones et al., 2008). Stratospheric warming is simulated by HadGEM1 following eruptions and compares favourably with observed changes (Stott et al., 2006). Some differences exist, but are probably due to phases of the QBO not simulated simultaneously by the model. 
We have chosen the Krakatau eruption of 1883 as the baseline eruption, because our mechanism may have special significance for it (see below). The parameterisation of stratospheric aerosol loading due to Krakatau's eruption displays many characteristics similar to other large tropical eruptions in climate models, such as spreading in the extratropics on a timescale of 1-2 years. It should therefore be quite general and applicable to many tropical eruptions.

The assumption in this study is that water vapour in the eruption plume rises to a height of $\sim 40 \mathrm{~km}$ (Francis and Self, 1983), and that excess SWV left over after combination with $\mathrm{SO}_{2}$ is evenly mixed in longitude. To simulate this in HadGEM1, we add $500 \mathrm{Mt}$ of water vapour to the model with a constant mixing ratio between $0-40 \mathrm{~km}$ and $10 \mathrm{~S}-0 \mathrm{~N}$ over a period of 10 days. The rationale for the zonally averaged shape is that while we wish to simulate the effect of a relatively confined pulse in the tropics, the timescale for such a pulse to travel zonally round the equator is very small. A constant mixing ratio is chosen as there is no information about vertical gradients in these sorts of anomalies. The total timeintegrated amount of water vapour artificially added to the model in this way in the stratosphere (above $100 \mathrm{hPa}$ ) is then 1.5 ppmv. Since water vapour is advected as a tracer in the GCM, the Brewer-Dobson circulation advects the anomaly polewards.

To assess the effects of interannual variability ensembles of model simulations are carried out using different initial conditions sampled from a long HadGEM1 simulation without any changing external forcing factors (Stott et al., 2006). Two scenarios are explored in the present work: the control run described above (denoted $\mathrm{V}$ because it includes the effect of a volcanic eruption), and $\mathrm{V}$ plus injected stratospheric water (denoted VSW). Each ensemble has 4 members, and for the following results the ensemble mean is used to estimate the mean climate change response, with the spread of the individual ensemble members used in the statistical analysis.

\section{Results}

Figure 2 shows the evolution of water vapour $q$ at the $50 \mathrm{hPa}$ level, taken as representative for the model stratosphere. The top panel shows $q$ in ensemble $\mathrm{V}$. A wet anomaly can be seen just after the eruption at the equator, which is consistent with volcanic aerosol warming the tropical tropopause layer, and allowing more water vapour into the stratosphere (e.g. Joshi and Shine, 2003).

The middle panel of Fig. 2 shows $q$ in the VSW ensemble. The $q$ anomaly is transported upwards and polewards by the mean circulation and down into the midlatitudes by the stratospheric Brewer-Dobson circulation. A smaller fraction of water vapour is transported into the southern midlatitudes than the northern midlatitudes because of the seasonal asymmetry of the Brewer Dobson circulation. The anomalies reach the polar regions $2-3$ years after the eruption, and decay over a timescale of 5-10 years, consistent with what would be expected of tracers advected away from the equatorial regions of the stratosphere (Hall and Waugh, 1997, Waugh and Hall, 2002).

The bottom panel of Fig. 2 shows the difference in ensembles average between VSW and V. There is significantly more water vapour at $50 \mathrm{hPa}$ in ensemble VSW than in V. Immediately after the eruption there is an excess of $2 \mathrm{ppmv}$ in the tropics, while even after 5 years the difference in the northern midlatitudes is $\mathrm{O}(1 \mathrm{ppmv})$, which is known to be enough to have climatically significant effects (Forster and Shine, 2002).

The change in energy balance is shown in Fig. 3. The radiative forcing has been calculated using a method, which was found to agree well with diagnosed forcings (Forster and Taylor, 2006). The method assumes that the net downward heat flux at the top of the atmosphere (TOA) is equal to the difference between the tropospheric radiative forcing and the climate feedback factor which is multiplied by the near surface temperature change. The climate feedback terms used for HadGEM1 are; $\mathrm{Y}_{\mathrm{LW}}=2.43 \mathrm{Wm}^{-2} \mathrm{~K}^{-1}$ and $\mathrm{Y}_{\mathrm{SW}}=1.05 \mathrm{Wm}^{-2} \mathrm{~K}^{-1}$ (Forster and Taylor, 2006); these were deduced from increasing $\mathrm{CO}_{2}$ concentration simulations so there is an implicit assumption that the same values are valid for other forcing factors. By using the TOA fluxes and near surface $(1.5 \mathrm{~m})$ temperatures obtained from the model simulations, the radiative forcings can be calculated. The left panel shows the long-wave or LW change, the middle panel the short-wave or SW change, and the sum is shown on the right panel. A clear SW cooling can be seen in $\mathrm{V}$ (in red), which is partially compensated for by LW heating, as volcanic aerosol does display some LW effects (see e.g. Ramachandran et al., 2000). The water vapour anomaly in VSW (shown in blue) exerts a globally averaged LW radiative forcing of $+0.33 \pm 0.09 \mathrm{Wm}^{-2}$ for the average of the two years following the eruption, which is consistent with the humidity anomaly shown in Fig. 2 (bottom) and previous work (Forster and Shine, 2002). The positive LW forcing also appears to last longer in VSW than V, consistent with the lifetime of the stratospheric water vapour anomaly being longer than the lifetime of the volcanic aerosol. There is very little SW effect, again consistent with stratospheric water vapour anomaly effects being felt mainly in the LW.

The near-surface response with respect to SWV amount is shown in Fig. 4, which shows the evolution of temperature at $1.5 \mathrm{~m}$ above the surface (a standard climatological measure) in each ensemble member. The ensemble mean (thick lines) is the best estimate of the mean climate changes. The globally averaged change shows that the effect of the water vapour anomaly in VSW is to warm the climate relative to V. The 2 year average following the eruption is $0.10 \mathrm{~K}$ warmer in VSW; a t-test gives a probability ( $\mathrm{p}$ value) of 0.06 that the model ensemble mean of VSW is not warmer than V, that is there is only a $6 \%$ chance that the difference between the ensemble means is due to internal variability alone. VSW is 
a)

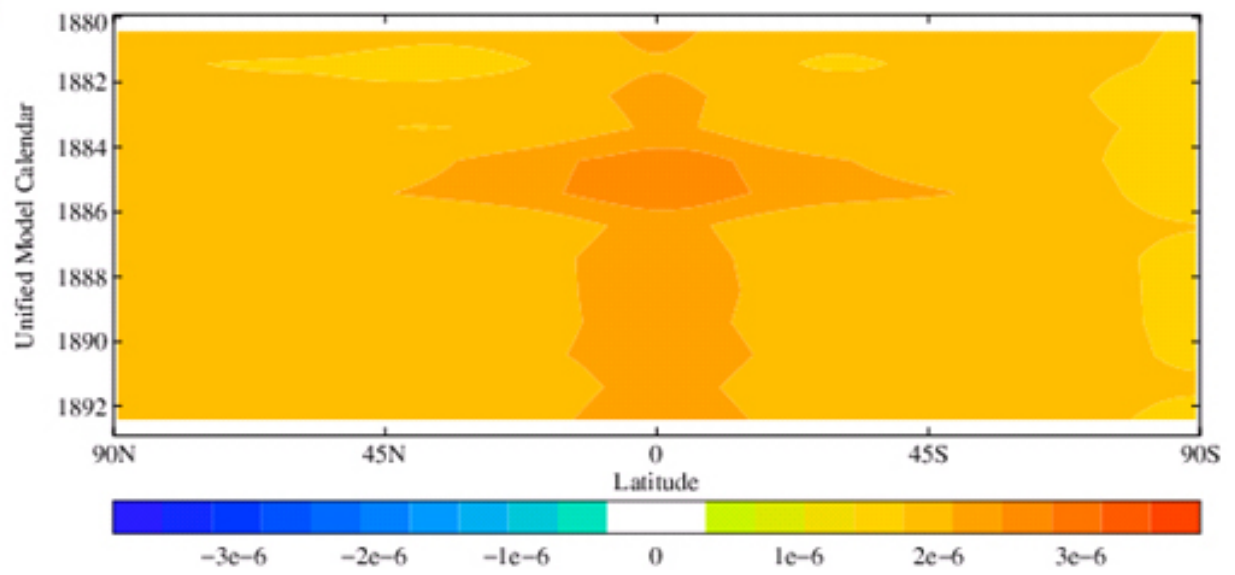

b)

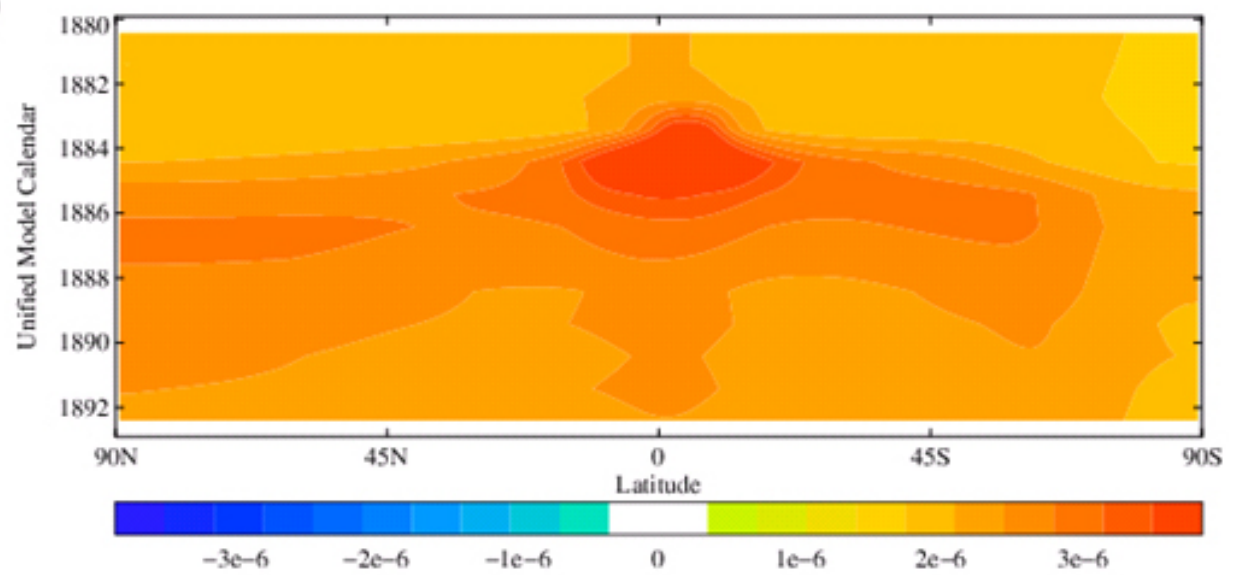

c)

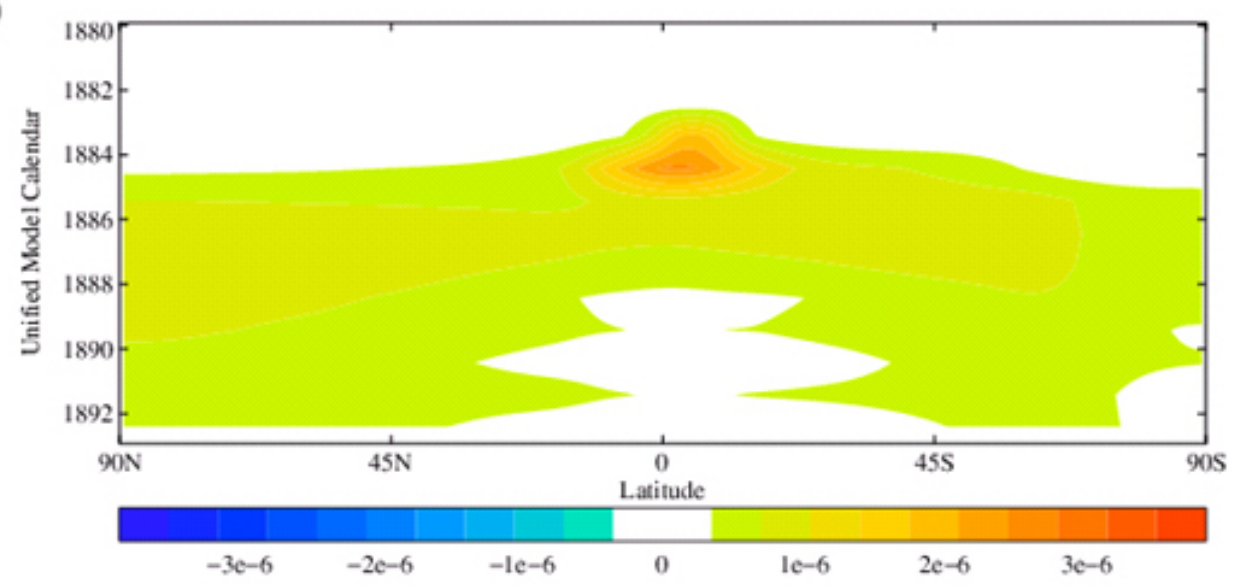

Fig. 2. Zonal cross sections of evolution of stratospheric humidity (ppm) at $50 \mathrm{hPa}$ in ensemble V (top), VSW (middle), and VSW minus V (bottom). The time of the eruption is given as 1883 in order to aid comparison with Krakatau.

warmer in the northern and southern hemispheres by $0.10 \mathrm{~K}$ and $0.12 \mathrm{~K}$ respectively for the average of the $1884-1885$ period. A t-test gives $\mathrm{p}$ values of 0.16 and 0.03 that the water anomaly does not warm the model mean for the northern and southern hemispheres respectively. Again, ensemble VSW appears to stay warmer than ensemble $\mathrm{V}$ for 5-10 years after the eruption, consistent with the lifetime of the stratospheric vapour anomaly shown in Fig. 2.

The zonally averaged temperature response is shown in Fig. 5. The exaggerated cooling in ensemble $\mathrm{V}$ is reduced in 

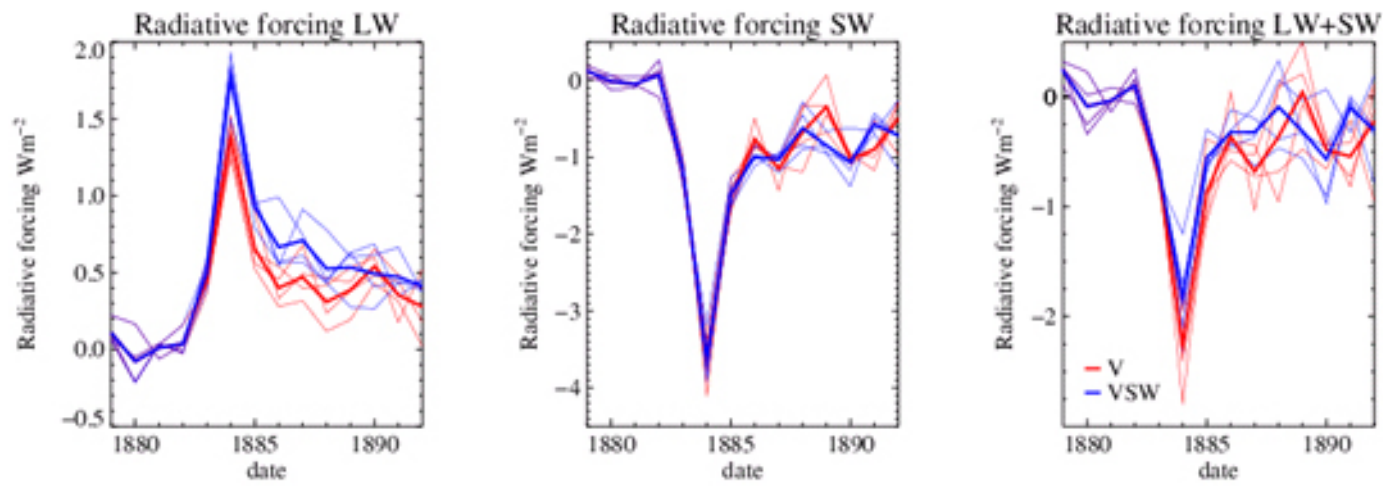

Fig. 3. Left: evolution of the LW radiative balance using the Forster \& Taylor method in ensemble V (red) and VSW (blue); middle: for the SW radiative balance; right: $\mathrm{LW}+\mathrm{SW}$. Individual ensemble members, thin lines and the ensemble averages thick lines.
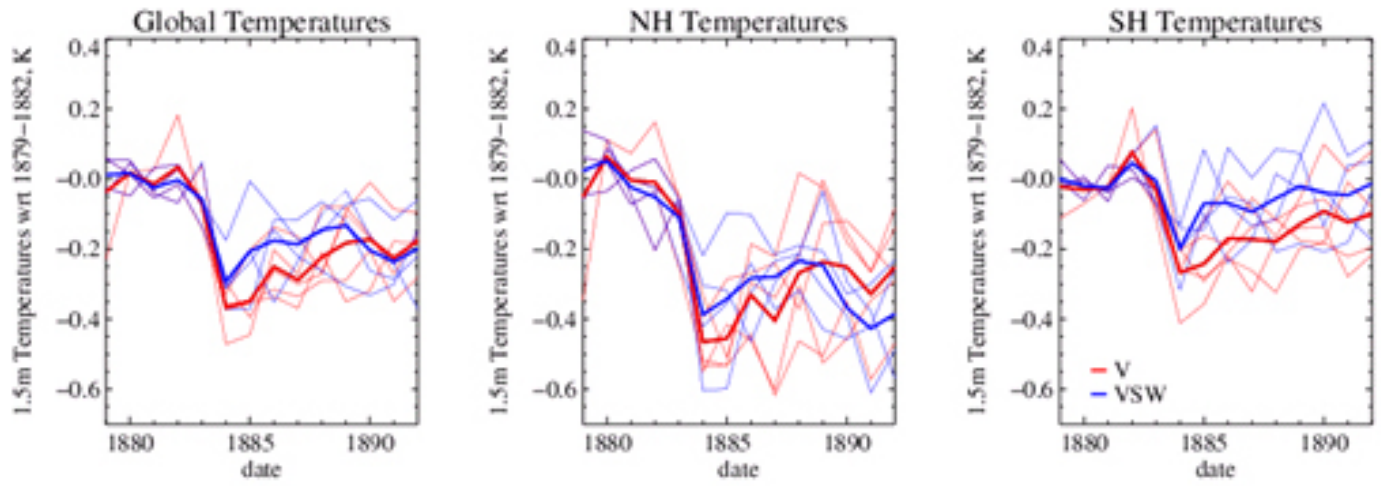

Fig. 4. As in Fig. 3 but the evolution of the globally averaged $1.5 \mathrm{~m}$ temperatures (left) $\mathrm{NH}$ temperatures (middle); and SH temperatures (right). Temperatures plotted with respect to 1879-1882 mean.

ensemble VSW, especially in the northern midlatitudes and polar regions- this is apparent from examining the difference in cooling patterns (Fig. 5c).

\section{Discussion and implications for Krakatau}

The water content of the magma, entrainment of water into the eruptive column, and even the season of the eruption significantly affect the amount and distribution of water vapour in the stratosphere 1-2 years after the eruption itself, and hence change the amount of surface cooling compared to the effect of stratospheric aerosol alone. It is also unclear how the amount of water vapour injected into the stratosphere might scale with other factors such as eruptive column height, or the scale of pyroclastic flows and the resulting coignimbrite plumes. Such uncertainties might prove to be significant, and will be investigated in future. The effects of stratospheric chemistry could also be included in any future work. For instance SWV depletes ozone, and this effect would be a small net negative radiative forcing the climate.

This work has special significance when applied to the eruption of Krakatau in 1883, which was one of the largest eruptions of modern times (Robock, 2000). The amount of magma produced by the eruption is thought to be 2 3 times as large as the amount produced by the eruption of Mt Pinatubo in 1991 (Self and Rampino, 1981; Scaillet et al., 2003). There are varied estimates of the amount of sulphur produced from the Krakatau and Pinatubo eruptions (Scaillet et al., 2003), but a reconstruction of the optical depth of the stratosphere due to volcanic sulphate aerosols is similar between the two eruptions (Sato et al., 1993). General circulation models (GCMs) consistently overestimate the globally averaged climatic cooling due to this eruption (Knutson et al., 2006; Miles et al., 2004; Stenchikov et al., 2006); such an overestimation is puzzling in the light of the fidelity with which climate models simulate the climatic cooling following the Mt Pinatubo eruption in 1991 (Randall et al., 2007).

Figure 6 shows observed near surface temperatures following Krakatau's eruption, and their associated uncertainties (Brohan et al., 2006; Rayner et al., 2006), together with simulated temperatures from the World Climate Research Programme's (WCRP's) Coupled Model Intercomparison Project phase 3 (CMIP3) multi-model dataset. Only those models that simulated volcanic eruptions by changing 
a)

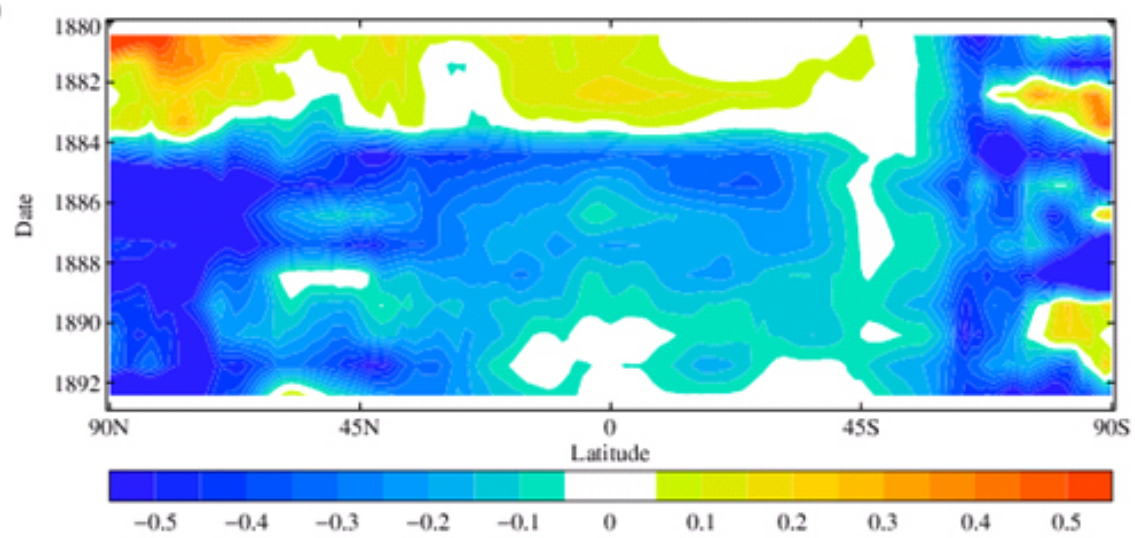

b)

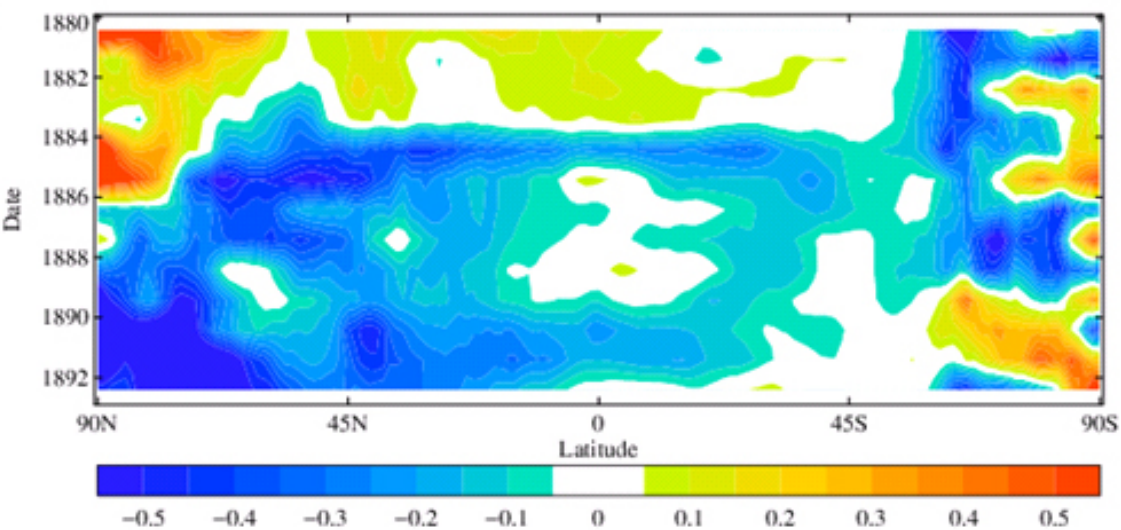

c)

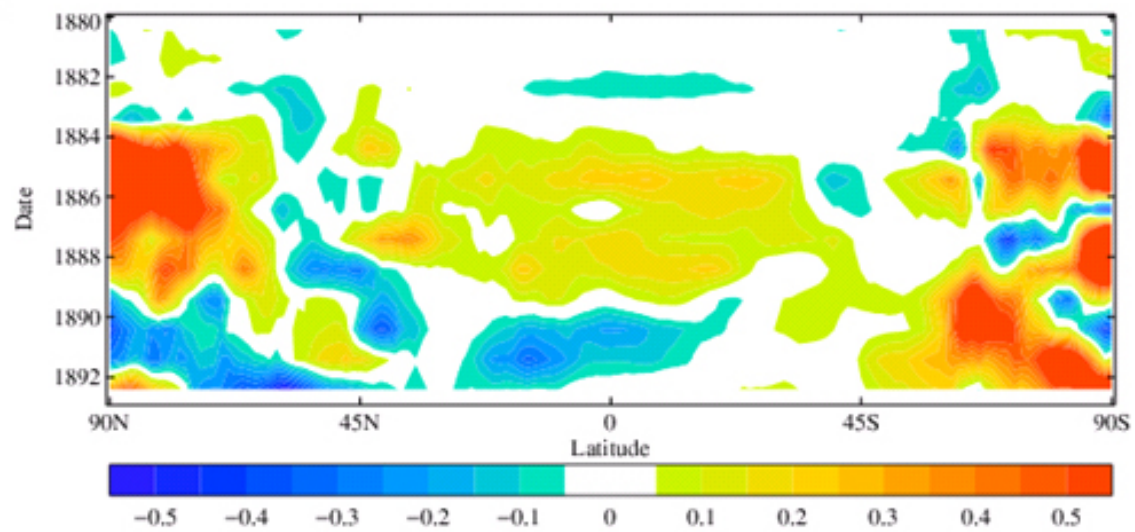

Fig. 5. Zonal cross sections of $1.5 \mathrm{~m}$ temperature anomaly minus the $1860-1880$ average in ensemble V (top), ensemble VSW (middle), and VSW minus V (bottom)The model is sampled in the same way as the observations.

the aerosol amounts in the stratosphere are included. The CMIP3 models consistently cool more than was observed. The HadGEM1 (V) simulated temperatures are also plotted in Fig. 6, and similarly show a larger cooling $(-0.35 \mathrm{~K})$ than observed $(-0.12 \pm 0.21 \mathrm{~K})$ for the global 2 year mean following the eruption.
A number of theories have been put forward to explain this discrepancy. Perhaps the radiative forcing was lower than estimated due to lower amounts of stratospheric aerosols than deduced from datasets (Sato et al., 1993). However there were substantial optical effects following Krakatau suggestive of substantial aerosol amounts in the stratosphere (Francis, 2000). Natural variability such as the El Niño Southern Oscillation (ENSO) in both the observations and the GCMs 
has been put forward as a reason why the GCMs might actually only appear to overestimate surface cooling. Reconstructions of Niño-3 index (sea surface temperature or SST anomaly between $210^{\circ} \mathrm{E}-270^{\circ} \mathrm{E}, 5^{\circ} \mathrm{S}-5^{\circ} \mathrm{N}$ ) do suggest an ENSO peaking in 1885 (Angell, 1988; Mann et al., 2000). However, the time-averaged Niño3 index in 1884-1885 was only approximately $0.6 \mathrm{~K}$, suggesting a weak ENSO event with accompanying global air temperature anomalies of about $+0.1 \mathrm{~K}$. Additionally, globally-averaged air temperature anomalies tend to lag the SST anomaly by a few months. It is therefore doubtful that an ENSO event can explain the discrepancy between the models and observations in the two years following the eruption.

Recent work has suggested that GCMs underestimate northern Eurasian warming following volcanic eruptions because they underestimate the increase in the Arctic Oscillation (AO) index associated with stratospheric volcanic aerosol (Stenchikov et al., 2006). However, given the limited spatial and seasonal scale of the anomalies, this effect cannot account for the globally and annually averaged temperature discrepancy.

A recent study describing the GISS modelE simulation suggested a number of possible contributing factors to the apparent discrepancy (Hansen et al., 2007), although they do conclude that there is a reasonable agreement with their model. Starting a model simulation from an initial state that has cooled from previous eruptions, which is not done in many of the CMIP3 simulations, may reduce the simulated response to Krakatau by $10 \%$. However HadGEM1 was initialised from a control simulation that incorporated a mean volcanic aerosol, which may explain why $\mathrm{V}$ cools slightly less than the average of the CMIP3 models (Fig. 6). There is an uncertainty on the level of the direct radiative forcing from the volcanic aerosols, which the GISS study estimates as $\pm 50 \%$. Using a different observational data set than used here, they suggest that as the observed cooling over land and over SSTs following the 1991 Pinatubo eruption agree and that there may be an issue of the accuracy of the SSTs in the 1880s. However the estimates of observational uncertainty used here suggest that SST global means are more accurately known than land global mean temperatures (Brohan et al., 2006), mainly due to the larger coverage of SST observations at the time.

We hypothesise that the Krakatau eruption plume was different to that of Pinatubo because of the proximity of the former volcano to the sea, and the entrainment of significantly larger amounts of water into the coignimbrite clouds associated with the pyroclastic flows that surged over the sea for distances of upto $80 \mathrm{~km}$ away from Krakatau (Carey et al., 1996). An injection of $500 \mathrm{Mt}$ of water into the stratosphere is a reasonable number for Krakatau given the different estimates for water entering the stratosphere after different eruptions in previous studies (see above). The fact that pyroclastic flows following the eruption of Mt. Pinatubo did not reach the ocean is the crucial difference between the two volcanoes

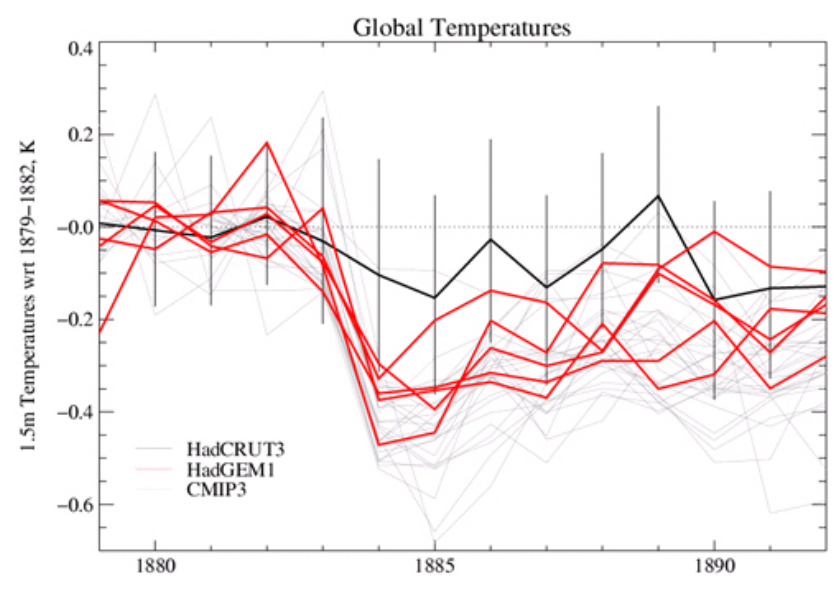

Fig. 6. Global mean temperatures with respect to 1879-1882 mean. Observed temperatures (black) shown with estimate of observational uncertainty (95\% range) as vertical bars. CMIP3 "20th century simulations" shown in grey. Only those models that simulated volcanic eruptions by changing the aerosol amounts in the stratosphere are included. HadGEM1 V ensemble members shown in red.

in this context (Scott et al., 1996), rather than the ambient tropospheric humidity, which would have been similar in both cases.

Figure 7 shows the observed temperature changes with both the V and VSW simulations for the globe, $\mathrm{NH}$ and $\mathrm{SH}$. For the V simulation the uncertainties (estimated to examine the difference between the observations and the ensemble mean of the simulations; these uncertainties are larger than used to estimate the significance between the ensemble means of the two simulations described above) on the global mean and $\mathrm{NH}$ temperatures do not overlap with the observed temperatures for the two years following the eruption, but they do for the VSW simulation. For the SH in the two years following the eruption, the VSW simulation is in better agreement than the $\mathrm{V}$ simulation, but the uncertainties are large enough that both simulations are consistent with the observations. The VSW simulation shows less cooling than the $\mathrm{V}$ simulation and is nearer the observed values.

Interestingly, there is some evidence that noctilucent clouds, which form at heights of $75-85 \mathrm{~km}$, were observed for the first time two years after Krakatau's eruption in 1885 (Schroder, 1999). While this evidence is circumstantial, we note that a wet anomaly at the tropopause in 1883 would need over 3 years just to reach the stratopause (Hall and Waugh, 1997). However, a wet anomaly at the top of the eruption plume at a height of $30-35 \mathrm{~km}$ could have reached the heights where noctilucent clouds form by 1885 if transported by a mean vertical velocity of $\mathrm{O}(1) \mathrm{mms}^{-1}$, which is consistent with velocities found in the mesosphere (e.g. Huang et al., 1991).

Inclusion of the climatic effects of water vapour injection has consequences for changes in heat content and sea level in 

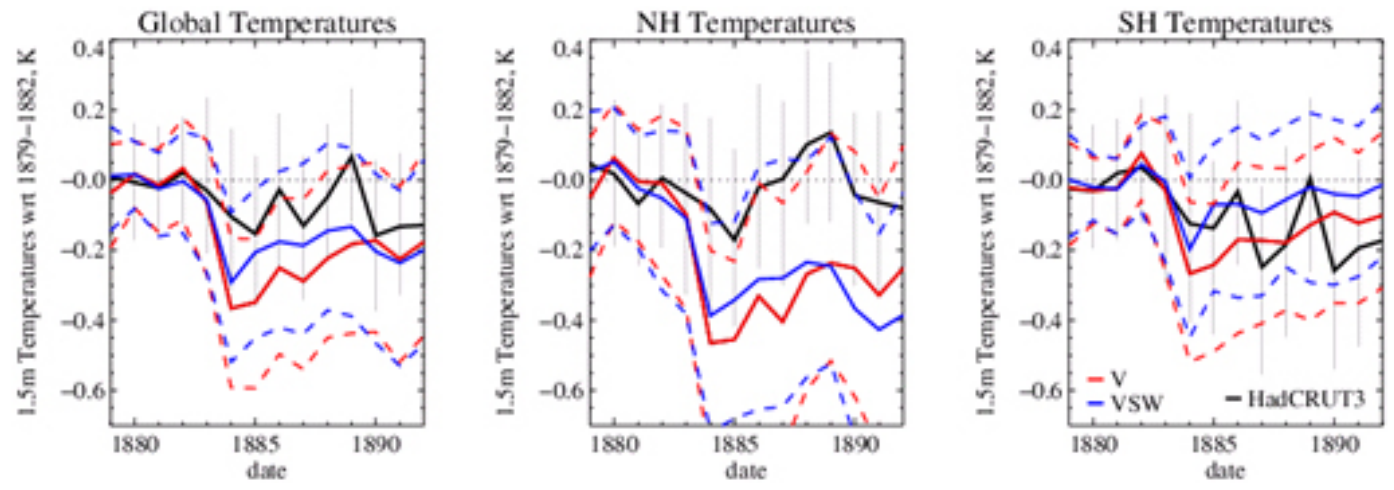

Fig. 7. Global mean, northern hemisphere and southern hemisphere observed temperatures with respect to 1879-1882 mean. HadGEM1 $\mathrm{V}$ ensemble average shown in red. Uncertainties (95\% range) around the simulation ensemble mean are estimates of how the observations would be distributed if they were sampled from the model ensemble, shown as red dashed line. HadGEM1 VSW is as HadGEM1 V but shown in blue. Vertical lines estimate of observational uncertainty (Brohan et al., 2006; Rayner et al., 2006).

the world's oceans during the 20th century. Previous studies have suggested that the oceans were affected by Krakatau's cooling for some decades (e.g. Gleckler et al., 2006). If the cooling associated with Krakatau is indeed less than the models suggest because of the mechanism explained above, model predictions of 20th century heat content and sea level change may be biased.

\section{Conclusions}

We have shown, using plausible volcanic inventories, that some large volcanic eruptions can potentially deposit a climatically significant amount of water in the stratosphere. The effect is a warming, i.e. it is a negative feedback to the cooling associated with the stratospheric volcanic aerosol. We hypothesize that the proximity of a given volcano to the sea allows pyroclastic flows over open ocean: water vapour is then entrained into the coignimbrite clouds than rise from these pyroclastic flows, and is transported upwards to the stratosphere. This mechanism can account for some of the difference between the observed and modelled temperature changes following the eruption of Krakatau in 1883. We stress that this explanation is one of a number of explanations: however, our hypothesis is a plausible explanation given what is conjectured about eruptions near large bodies of water (Francis and Self, 1983). Additionally, the circumstantial evidence for increased amounts of water in the middle atmosphere following the Krakatau eruption in the form of noctilucent clouds (Schroder, 1999) is consistent with this hypothesis.

This mechanism has implications for the climatic perturbation resulting from the eruption of other volcanoes near large bodies of water, such as Agung in 1963, or even the eruption of Toba $70 \mathrm{kyr}$ ago. Injections of large amounts of water vapour into the stratosphere might significantly counterbalance the cooling effect associated with such volcanic eruptions. Future research will involve investigating these effects.

Acknowledgements. This work is supported by the UK Department for Environment, Food and Rural Affairs (Defra) contract number PECD/7/12/37 and the NERC NCAS climate programme. We would like to thank L. Glaze, F. Prata, S. Self and the other reviewers of the original manuscript for comments that resulted in significant improvements. We acknowledge the modelling groups, the Program for Climate Model Diagnosis and Intercomparison and the WCRP's Working Group on Coupled Modelling for their roles in making available the WCRP CMIP3 multi-model dataset. Support of the CMIP3 dataset is provided by the Office of Science, U.S. Department of Energy. We would also like to thank Chris Sear for his contributions.

Edited by: P. Haynes

\section{References}

Angell, J. K.: Impact of El Niño on the delineation of tropospheric cooling due to volcanic eruptions, J. Geophys. Res., 93, 36973704, 1988.

Bekki, S., Pyle, J. A., Zhong, W., Toumi, R., Haigh, J. D., and Pyle, D. M.: The role of microphysical and chemical processes in prolonging the climate forcing of the Toba eruption, Geophys. Res. Lett., 23(19), 2669-2672, 1996.

Brohan, P., Kennedy, J. J., Harris, I., Tett, S. F. B., and Jones, P. D.: Uncertainty estimates in regional and global observed temperature changes: a new dataset from 1850, J. Geophys. Res., 111, D12106, doi:10.1029/2005JD006548, 2006.

Carey, S., Sigurdsson, H., Mandeville, C., and Bronto, S.: Pyroclastic flows and surges over water: an example from the 1883 Krakatau eruption, B. Volcanol., 57(7), 493-511, 1996.

Dall Amico, M., Gray, L. J., Rosenlof, K. H., Scaife, A. A., Shine, K. P., and Stott, P. A.: Stratospheric temperature trends: impact of ozone variability and the QBO, J. Climate, in press, 2009. 
Dartevelle, S., Ernst, G. G. J., Stix, J., and Bernard, A.: Origin of the Mount Pinatubo climactic eruption cloud: implications for volcanic hazards and atmospheric impacts, Geology, 30, 663666, 2002.

Forster, P. M. de F. and Shine, K. P.: Assessing the climate impact of trends in stratospheric water vapour, Geophys. Res. Lett., 29(6), 1086, doi:10.1029/2001GL013909, 2002.

Forster, P. M. de F. and Taylor, K. E.: Climate Forcings and Climate Sensitivities Diagnosed from Coupled Climate Model Integrations, J. Climate, 19, 6181-6194, 2006.

Francis, P. and Self, S.: The eruption of Krakatau, Sci. Am., 249, 146-159, 1983.

Francis, P.: Volcanoes: a planetary perspective, Clarendon press, Oxford, 2000.

Glaze, L. S., Baloga, S. M., and Wilson, L.: Transport of atmospheric water vapor by volcanic eruption columns, J. Geophys. Res., 102, 6099-6108, 1997.

Gleckler, P. J., AchutaRao, K., Gregory, J. M., Santer, B. D., Taylor, K. E., and Wigley, T. M. L.: Krakatau lives: The effect of volcanic eruptions on ocean heat content and thermal expansion, Geophys. Res. Lett., 33, L17702, doi:10.1029/2006GL026771, 2006.

Hall, T. M. and Waugh, D. W.: Timescales for the stratospheric circulation derived from tracers, J. Geophys. Res., 102, 89919001, 1997.

Hansen, J., Sato, M., Ruedy, R., et al.: Climate simulations for 1880-2003 with GISS modelE, Clim. Dynam., 29, 661-696, 2007.

Huang, T. Y. W. and Smith, A. K.: The Mesospheric Diabatic Circulation and the Parameterized Thermal Effect of Gravity Wave Breaking on the Circulation, J. Atmos. Sci., 48, 1093-1111, 1991.

Johns, T. C., Durman, C. F., Banks, H. T., et al.: The new Hadley Centre climate model HadGEM1: Evaluation of coupled simulations, J. Climate, 19, 1327-1353, 2006.

Jones, G. S., Stott, P. A., and Christidis, N.: Human contribution to rapidly increasing frequency of very warm Northern Hemisphere summers, J. Geophys. Res., 113, D02109, doi:10.1029/2007JD008914, 2008.

Joshi, M. M. and Shine, K. P.: A GCM study of volcanic eruptions as a cause of increased stratospheric water vapour, J. Climate, 16, 3525-3534, 2003.

Joshi, M. M., Charlton, A. J., and Scaife, A. A.: On the influence of stratospheric water vapour changes on the tropospheric circulation, Geophys. Res. Lett., 33, L09806, doi:10.1029/2006GL025983, 2006.

Knutson, T. R., Delworth, T. L., Dixon, K. W., Held, I. M., Lu, J., Ramaswamy, V., Schwarzkopf, M. D., Stenchikov, G., and Stouffer, R. J.: Assessment of twentieth-century regional surface temperature trends using the GFDL CM2 coupled models, J. Climate, 19, 1624-1651, 2006.

Mann, M. E., Bradley, R., Hughes, M., et al.: Global Temperature Patterns in Past Centuries: An Interactive Presentation, IGBP Pages/World Data Center for Paleoclimatology Data Contribution Series \#2000-075, NOAA/NGDC Paleoclimatology Program, Boulder CO, USA, 2000.

Martin, G. M., Ringer, M. A., Pope, V. D., Jones, A., Dearden, C., and Hinton, T. J.: The Physical Properties of the Atmosphere in the New Hadley Centre Global Environmental Model
(HadGEM1). Part I: Model Description and Global Climatology, J. Climate, 19, 1274-1301, 2006.

Miles, G. M., Grainger, R. G., and Highwood, E. J.: The significance of volcanic eruption strength and frequency for climate, Q. J. Roy. Meteor. Soc., 130, 2361-2374, 2004.

Nedoluha, G. E., Bevilacqua, R. M., Gomez, R. M., Siskind, D. E., Hicks, B. C., Russell, J. M., and Connor, B. J.: Increases in middle atmosphere water vapor as observed by the Halogen Occultation Experiment and the ground-based Water Vapor Millimeterwave Spectrometer from 1991 to 1997, J. Geophys. Res., 103, 3531-3543, 1998.

Pitari, G. and Mancini, E.: Short term climatic impact of the 1991 volcanic eruption of Mt Pinatubo and effects on atmospheric tracers, Nat. Hazards Earth Syst. Sci., 2, 91-108, 2002, http://www.nat-hazards-earth-syst-sci.net/2/91/2002/.

Randall, D. A., Wood, R. A., Bony, S., Colman, R., Fichefet, T., Fyfe, J., Kattsov, V., Pitman, A., Shukla, J., Srinivasan, J., Stouffer, R. J., Sumi, A., and Taylor, K. E.: Climate Models and Their Evaluation, in: Climate Change 2007: The Physical Science Basis. Contribution of Working Group I to the Fourth Assessment Report of the Intergovernmental Panel on Climate Change, edited by: Solomon, S., Qin, D., Manning, M., Chen, Z., Marquis, M., Averyt, K. B., Tignor, M., and Miller, H. L., Cambridge University Press, Cambridge, United Kingdom and New York, NY, USA, 2007.

Ramachandran, S., Ramaswamy, V., Stenchikov, G. L., and Robock, A.: Radiative impacts of the Mt. Pinatubo volcanic eruption: Lower stratospheric response, J. Geophys. Res., 105, 24 409-24 429, 2000.

Rayner, N. A., Brohan, P., Parker, D. E., Folland, C. K., Kennedy, J. J., Vanicek, M., Ansell, T., and Tett, S. F. B.: Improved analyses of changes and uncertainties in sea surface temperature measured in situ since the mid-nineteenth century: the HadSST2 data set, J. Climate, 19, 446-469, 2006.

Robock, A.: Volcanic Eruptions and climate, Rev. Geophys., 38, 191-219, 2000.

Sato, M., Hansen, J. E., McCormick, M. P., and Pollack, J. B.: Stratospheric aerosol optical depths, 1850-1990, J. Geophys. Res., 98, 22 987-22 994, 1993.

Scaillet, B., Luhr, J., and Carroll, M. R.: Petrological and Volcanological constraints on volcanic sulfur emissions to the atmosphere, in Volcanism and the Earth's atmosphere, Geophysical monograph, 19, 11-40, 2003.

Schroder, W.: Were noctilucent clouds caused by the Krakatau eruption? A case study of the research problems before 1885, B. Am. Meteorol. Soc., 80, 2081-2085, 1999.

Scott, W. E., Hoblitt, R. P., Torres, R. C., Self, S., Martinez, M. L., and Nillos Jr., T.: Pyroclastic flows of the June 15, 1991, climactic eruption of Mount Pinatubo, in: Fire and Mud: Eruptions and Lahars of Mount Pinatubo, Philippines, edited by: Newhall, C. G. and Punongbayan, R. S., Quezon City, Philippines: Philippine Inst. Volc. Seism., and Seattle: Univ. Wash. Press, 545-570, 1996.

Self, S. and Rampino, M. R.: The 1883 eruption of Krakatau, Nature, 294, 699-704, 1981.

Stenchikov, G., Hamilton, K., Stouffer, R. J., Robock, A., Ramaswamy, V., Santer, B., and Graf, H. F.: Arctic Oscillation response to volcanic eruptions in the IPCC AR4 climate models, J. Geophys. Res., 111, D07107, doi:10.1029/2005JD006286, 2006. 
Stott, P. A., Jones, G. S., Lowe, J. A., Thorne, P., Durman, C., Johns, T. C. and Thelen, J. C.: Transient simulations of HadGEM1 using historic and SRES scenarios, J. Climate, 19, 2763-2782, 2006.
Waugh, D. W. and Hall, T. M.: Age of stratospheric air: theory, observations and models, Rev. Geophys., 40(4), 1010, doi:10.1029/2000RG000101, 2002.

Woods, A. W. and Wohletz, K.: Dimensions and dynamics of coignimbrite eruption columns, Nature, 350, 225-227, 1991. 